\title{
Utilização do triticale e de enzimas em dietas para suínos: digestibilidade e metabolismo
}

[Utilization of triticale and of enzymes in pig diets: digestibility and metabolism]

\author{
L. Hauschild $^{1}$, P.A. Lovatto $^{1 *}$, C.R. Lehnen ${ }^{1,2}$, A.d'A. Carvalho ${ }^{1,2}$, L. Alebrante ${ }^{1}$ \\ ${ }^{1}$ Universidade Federal de Santa Maria \\ Faixa de Camobi, km \\ 97105-900 - Santa Maria, RS \\ ${ }^{2}$ Bolsista - CAPES
}

\begin{abstract}
RESUMO
Avaliou-se o efeito da inclusão de níveis de triticale sobre o valor nutritivo de dietas para suínos com ou sem enzimas. Foram utilizados 24 suínos machos, castrados, com peso inicial de 59kg, alojados em gaiolas metabólicas. O delineamento foi de blocos ao acaso em arranjo fatorial 3 × 2 (níveis de triticale, 0,30 e $60 \%$, com ou sem enzimas), com quatro repetições cada. A inclusão de triticale na dieta em até $60 \%$ e a adição de enzimas não influenciou $(\mathrm{P}>0,05)$ a digestibilidade da matéria seca, fósforo, energia bruta, metabolização da energia, energia digestível e metabolizável e o balanço do N. Os valores médios de energia digestível e metabolizável foram de 3.537 e $3.435 \mathrm{kcal}$. Houve interação triticale x enzimas na proteína digestível aparente $\left(\mathrm{PD}_{\mathrm{a}}\right)(\mathrm{P}<0,01)$. Na dieta com $60 \%$ de triticale sem adição de enzimas a $\mathrm{PD}_{\mathrm{a}}$ foi $6 \%$ inferior à controle. Na dieta com 30 e $60 \%$ de triticale com enzimas, a $\mathrm{PD}_{\mathrm{a}}$ foi similar à controle e $5 \%$ superior à dieta com $60 \%$ de triticale sem enzimas. A inclusão de $60 \%$ de triticale em dietas para suínos reduz a $\mathrm{PD}_{\mathrm{a}}$. A adição de enzimas melhora a $\mathrm{PD}_{\mathrm{a}}$ em dietas com 30 e $60 \%$ de triticale.
\end{abstract}

Palavras-chave: suíno, $\beta$-glucanase, fósforo, metabolizibilidade, nitrogênio, xilanase

\section{ABSTRACT}

The effect of triticale levels with or without enzyme supplementation on nutritive value of pig's diet was evaluated using twenty four barrows weighting 59kg, housed in metabolic crates. A complete randomized experimental block design in a $3 \times 2$ factorial arrangement (triticale levels $-0,30$ e $60 \%$ with or without enzymes) with four replicates each was utilized. No effects of triticale levels and enzymes supplementation $(P>0.05)$ were observed on dry matter digestibility, phosphorus, crude energy, metabolization of energy, digestible and metabolizable energy and nitrogen balance. The average values of digestible and metabolizable energy were 3,537 e 3,435kcal. An interaction triticale $x$ enzymes effect on apparent digestible protein $\left(D P_{a}\right)$ $(P<0.01)$ was observed. Apparent digestible protein for $60 \%$ triticale diets without enzymes supplementation was $6 \%$ lower than control diet while $D P_{a}$ of 30 and $60 \%$ triticale diets with enzymes supplementation were similar to $D P_{a}$ of the control diet and 5\% higher than $60 \%$ triticale diets without enzyme supplementation. The inclusion of $60 \%$ triticale in pig diets reduces the $D P_{a}$. Enzymes supplementation improves the $D P_{a}$ for diets containing 30 and $60 \%$ of triticale.

Keywords: swine, $\beta$-glucanase, phosphorus, metabolizibility, nitrogen, xylanase

\section{INTRODUÇÃO}

O milho é a principal fonte energética utilizada na alimentação de suínos. A escassez do milho na entressafra eleva seu custo, estimulando sua substituição nas dietas por alimentos alternativos. Assim, ingredientes com perfil nutricional

Recebido em 26 de março de 2007

Aceito em 29 de fevereiro de 2008

* Autor para correspondência (corresponding author)

E-mail: lovatto@smail.ufsm.br semelhante ao do milho, que não comprometam o desempenho animal, vêm sendo estudados (Fedalto et al., 1999; Hogberg e Lindberg, 2004).

O Rio Grande do Sul é um dos estados mais importantes na produção nacional de grãos. A localização geográfica do RS apresenta condições de clima e solo favoráveis à produção 
de culturas de inverno, com potencial para alimentação dos suínos. Dentre essas culturas, destaca-se o triticale, cereal que combina a qualidade protéica e energética do trigo com a rusticidade do centeio.

O triticale apresenta teor protéico $22 \%$ mais alto que o do milho, com um perfil melhor de aminoácidos, principalmente lisina (Nutrient..., 1998). Algumas variedades têm níveis de lisina $50 \%$ mais elevados que o milho, e seu uso pode diminuir em aproximadamente $3 \%$ a inclusão de farelo de soja nas dietas de suínos (Myer et al., 1996). O triticale melhora ainda a digestão do $P$ devido à atividade fitásica intrínseca (Pointillart, 1993).

Existem algumas limitações para o uso do triticale na alimentação de suínos devido aos polissacarídeos não amiláceos (PNA), que não são hidrolisados pelas enzimas digestivas (Bedford, 1995). O efeito negativo dos PNA na digestibilidade dos ingredientes deve-se ao aumento da viscosidade no trato gastrintestinal (Jorgensen et al., 1996). No entanto, a adição de complexos multienzimáticos do grupo das carboidrases (celulases, hemicelulases e xilanases) pode viabilizar a substituição do milho por triticale em rações de suínos. Essas enzimas reduzem a viscosidade da digesta e aumentam a digestibilidade dos alimentos (Fireman e Fireman, 1998). Outros fatores negativos do triticale têm sido relatados, dentre os quais os inibidores de tripsina (Brand et al., 1995), o baixo valor energético e a pouca palatabilidade (Shimada et al., 1974). Entretanto, as concentrações de inibidores de tripsina são baixas nas variedades de triticale cultivadas no Brasil (Beagle 82, BR-1, BR-2, BR-4).

A substituição de milho por triticale nas dietas para suínos em crescimento piora linearmente a conversão alimentar (Myer et al., 1989), mas não afeta o consumo de ração e o ganho de peso (Furlan et al., 1999). Os poucos trabalhos publicados mostram resultados variáveis e contraditórios do nível ideal de triticale a ser usado em dietas para suínos. Além disso, poucos estudos avaliaram o uso de triticale associado a enzimas na digestibilidade aparente das dietas e no metabolismo dos animais. Este trabalho teve por objetivo estudar a digestibilidade aparente das dietas e o balanço do nitrogênio de suínos alimentados com dietas contendo diferentes níveis de triticale com ou sem adição de enzimas.

\section{MATERIAL E MÉTODOS}

O experimento foi realizado entre outubro e novembro de 2004. Foram utilizados 24 suínos machos castrados, geneticamente homogêneos e irmãos paternos, oriundos de cruzamentos industriais entre as raças Landrace $\mathrm{x}$ Large White $\mathrm{x}$ Duroc. $\mathrm{O}$ peso vivo (PV) médio inicial foi de 59,29 , e o final de $69,8 \mathrm{~kg}$. Os animais foram alojados em gaiolas metabólicas, mantidas em ambiente semicontrolado em temperatura média de $22^{\circ} \mathrm{C}$. O delineamento experimental foi de blocos ao acaso, consistindo em um fatorial $3 \times 2$ (níveis de inclusão de triticale, 0, 30 e 60\%, com ou sem adição de enzimas), com quatro repetições por tratamento, tendo o animal como unidade experimental.

As dietas experimentais (Tab. 1) foram formuladas segundo o NRC (Nutrient..., 1998), sendo isoenergéticas, isoprotéicas, isocálcicas e isofosfóricas. Foram adicionadas $50 \mathrm{~g} / \mathrm{t}$ de ração de um complexo enzimático com atividades de xilanases e $\beta$-glucanases.

O experimento teve duração de 24 dias, divididos em dois períodos de 12 dias cada - sete de adaptação dos animais às gaiolas e ao alimento e cinco para coletas. As rações foram fornecidas de acordo com o peso metabólico $\left(\mathrm{PV}^{0,60}\right)$. A quantidade diária de ração foi ajustada de acordo com a estimativa do ganho médio diário, considerando um consumo de 2,6 vezes ao da mantença, estimada em $250 \mathrm{kcal} \mathrm{EM} / \mathrm{kg} \mathrm{PV}^{0,60}$ (Noblet et al., 1993). A ração foi fornecida em três refeições diárias, às 8,13 e $18 \mathrm{~h}$, e o acesso à água foi livre.

Foi utilizado o método de coleta total de fezes. O início e o final da coleta foram determinados pelo aparecimento de fezes marcadas (foram adicionados $1,5 \%$ de $\mathrm{Fe}_{2} \mathrm{O}_{3}$ às dietas). As fezes totais foram coletadas uma vez ao dia, acondicionadas em sacos plásticos e conservadas em congelador a $-10^{\circ} \mathrm{C}$. No final do experimento, as fezes foram homogeneizadas e amostradas $(0,5 \mathrm{~kg})$, secas em estufa de ventilação forçada $\left(60^{\circ} \mathrm{C} / 72 \mathrm{~h}\right)$ e moídas para análises posteriores. A urina excretada era drenada para baldes plásticos contendo $25 \mathrm{ml}$ de $\mathrm{HCl} 6 \mathrm{~N}$. A cada $12 \mathrm{~h}$, após homogeneização, o volume era medido e uma amostra de $5 \%$ era retirada e conservada sob refrigeração $\left(4^{\circ} \mathrm{C}\right)$. As análises químicas de fezes e urina foram realizadas segundo metodologia da AOAC (Official..., 1990). As variáveis avaliadas 
foram os coeficientes de digestibilidade aparentes da matéria seca $\left(\mathrm{CD}_{\mathrm{a}} \mathrm{MS}\right)$, de energia bruta $\left(\mathrm{CD}_{\mathrm{a}} \mathrm{EB}\right)$, de metabolizibilidade da energia (CME) e da proteína digestível aparente $\left(\mathrm{PD}_{\mathrm{a}}\right)$, de energia digestível aparente $\left(\mathrm{ED}_{\mathrm{a}}\right)$, a energia metabolizável aparente $\left(\mathrm{EM}_{\mathrm{a}}\right)$, o balanço do $\mathrm{N}$ e a digestibilidade do fósforo. Os valores de $\mathrm{CD}_{\mathrm{a}} \mathrm{MS}, \mathrm{CD}_{\mathrm{a}} \mathrm{EB}, \mathrm{CD}_{\mathrm{a}} \mathrm{PB}$, $\mathrm{CME}, \mathrm{ED}_{\mathrm{a}}$ e $\mathrm{EM}_{\mathrm{a}}$ foram determinados de acordo com metodologia proposta por Matterson et al. (1965).

Tabela 1. Composições calculada e analisada das rações experimentais para suínos contendo 0, 30 ou $60 \%$ de triticale ${ }^{1}$

\begin{tabular}{|c|c|c|c|}
\hline \multirow{2}{*}{ Ingrediente } & \multicolumn{3}{|c|}{ Dieta } \\
\hline & 0 & 30 & 60 \\
\hline Milho & 69,88 & 41,71 & 12,98 \\
\hline Triticale & 0,00 & 30,00 & 60,00 \\
\hline Farelo de soja & 25,09 & 22,31 & 20,12 \\
\hline Óleo vegetal & 2,02 & 2,97 & 3,95 \\
\hline L-lisina & 0,05 & 0,03 & 0,03 \\
\hline Suplemento vitamínico e mineral $^{2}$ & 3,00 & 3,00 & 3,00 \\
\hline \multicolumn{4}{|l|}{ Valor calculado } \\
\hline Energia metabolizável, kcal/kg & 3.265 & 3.265 & 3.265 \\
\hline Proteína bruta, $\%$ & 16,15 & 16,28 & 16,61 \\
\hline Cálcio, \% & 0,61 & 0,61 & 0,61 \\
\hline Fósforo total, $\%$ & 0,63 & 0,57 & 0,51 \\
\hline Lisina, $\%$ & 0,80 & 0,78 & 0,78 \\
\hline Metionina, $\%$ & 0,28 & 0,27 & 0,26 \\
\hline Treonina, $\%$ & 0,59 & 0,57 & 0,56 \\
\hline \multicolumn{4}{|l|}{ Valor analisado } \\
\hline Matéria seca, $\%$ & 86,33 & 86,01 & 86,18 \\
\hline Proteína bruta, $\%$ & 14,92 & 15,34 & 14,93 \\
\hline Extrato etéreo, $\%$ & 7,41 & 7,97 & 8,72 \\
\hline Fósforo total, \% & 0,87 & 0,82 & 0,93 \\
\hline Fibra bruta, $\%$ & 3,80 & 3,77 & 3,92 \\
\hline Energia bruta, kcal $/ \mathrm{kg}$ & 3.968 & 3.993 & 4.023 \\
\hline
\end{tabular}

${ }^{\mathrm{T}}$ Matéria natural, composição dos alimentos segundo Rostagno et al. (2000); ${ }^{2}$ Composição por kg de produto): vit.A: 94.000UI; vit.B2: $106 \mathrm{mg}$; vit.B6: 36mg; vit.B12: 770mg; vit.D3: $17.000 U I$; vit.E: 420mg; vit.K3: 37mg; ác. Nicotínico: 554mg; ác. Pantotênico: 274mg; Ca: 180g; P: 64g; Na: 44g; Co: 18mg; Cu: 2000mg; F: 636mg; Fe: 2100mg; I: 37mg; Mn: 1224mg; Se: 7mg; Zn: 2072mg; promotor de crescimento: $1250 \mathrm{mg}$; antioxidante: $400 \mathrm{mg}$.

Os dados obtidos foram submetidos à análise de variância usando o procedimento GLM do SAS (User's..., 2000). As comparações de médias foram feitas pelo teste Tukey.

\section{RESULTADOS E DISCUSSÃO}

O triticale apresentou $88 \%$ de MS, $11,2 \%$ de proteína bruta $(\mathrm{PB}), 0,01 \%$ de cálcio $(\mathrm{Ca})$ e $0,20 \%$ de fósforo $(\mathrm{P})$. Estes valores foram mais baixos em $0,50 \%$ de MS, $0,86 \%$ de PB, $0,03 \%$ de $\mathrm{Ca}$ e $0,04 \%$ de $\mathrm{P}$ em relação aos propostos pelo Nutrient... (1998) e Rostagno et al. (2005). Essas variações eram esperadas, pois a composição química do triticale pode variar em função de fatores como cultivar, solo e clima (Owsley et al., 1987).
Os resultados de digestibilidade aparente da MS, $\mathrm{PB}$ e energia bruta (EB), energias digestível (ED) e metabolizável (EM) aparentes e a metabolizibilidade da energia são apresentados na Tab. 2. A inclusão de triticale e a adição de enzimas não afetaram $(\mathrm{P}>0,05)$ a digestibilidade e a metabolizibilidade da energia. Houve interação triticale $\mathrm{x}$ enzimas $(\mathrm{P}<0,01)$ na proteína digestível aparente (Tab. 3). $\mathrm{Na}$ dieta com inclusão de $60 \%$ de triticale sem adição de enzimas, a $\mathrm{PD}_{\mathrm{a}}$ foi $6 \%$ menor que a da dietacontrole. No entanto, na dieta com 30 e $60 \%$ de triticale com adição de enzimas, a $\mathrm{PD}_{\mathrm{a}}$ foi similar à controle e $5 \%$ mais elevada que a da dieta com $60 \%$ de triticale sem enzimas. 
Tabela 2. Coeficientes de digestibilidade aparente da matéria seca $\left(\mathrm{CD}_{\mathrm{a}} \mathrm{MS}\right)$ e da energia bruta $\left(\mathrm{CD}_{\mathrm{a}} \mathrm{EB}\right)$, coeficiente de metabolizibilidade da energia bruta $(\mathrm{CME})$, energia digestível aparente $\left(\mathrm{ED}_{\mathrm{a}}\right)$ e energia metabolizável aparente $\left(\mathrm{EM}_{\mathrm{a}}\right)$ de dietas de suínos contendo diferentes níveis de inclusão de triticale com ou sem adição de enzimas

\begin{tabular}{lccccc}
\multicolumn{1}{c}{ Dieta } & $\mathrm{CD}_{a} \mathrm{MS}$ & $\mathrm{CD}_{a} \mathrm{~EB}$ & $\mathrm{CME}$ & $\mathrm{ED}_{\mathrm{a}}$ & $\mathrm{EM}_{\mathrm{a}}$ \\
\hline Nível de triticale & & & & & \\
$\quad 0 \%$ & 89,80 & 88,76 & 88,55 & 3.522 & 3.429 \\
$30 \%$ & 89,25 & 88,42 & 88,56 & 3.528 & 3.412 \\
$\quad 60 \%$ & 89,54 & 88,74 & 89,82 & 3.566 & 3.469 \\
\hline Enzima & & & & & \\
$\quad$ Sem enzimas & 89,72 & 88,71 & 89,52 & 3.541 & 3.438 \\
$\quad$ Com enzimas & 89,36 & 88,57 & 88,31 & 3.534 & 3.433 \\
EPR & 0,46 & 0,69 & 1,41 & 25,71 & 38,15 \\
P & & & & & \\
$\quad$ Triticale & 0,49 & 0,86 & 0,77 & 0,31 & 0,39 \\
Enzimas & 0,50 & 0,90 & 0,28 & 0,78 & 0,83 \\
$\quad$ Triticale x enzimas & 0,06 & 0,09 & 0,19 & 0,13 & 0,74 \\
\hline
\end{tabular}

EPR: erro-padrão residual.

Tabela 3. Proteína digestível aparente de dietas de suínos contendo diferentes níveis de inclusão de triticale com ou sem adição de enzimas

\begin{tabular}{ccc}
\hline \multirow{2}{*}{ Nível de triticale } & \multicolumn{2}{c}{ Proteína digestível aparente, \% } \\
\cline { 2 - 3 } & \multicolumn{1}{c}{ Sem enzimas } & Com enzimas \\
$30 \%$ & $13,74 \mathrm{a}$ & $12,40 \mathrm{c}$ \\
$60 \%$ & $13,40 \mathrm{ab}$ & $13,60 \mathrm{a}$ \\
& $12,93 \mathrm{bc}$ & \\
\hline EPR & & $0,13,56 \mathrm{a}$ \\
\hline $\mathrm{P}$ & & \\
Triticale x enzimas & & 0,0001
\end{tabular}

Valores seguidos por letras distintas na coluna e na linha diferem entre si pelo Teste Tukey $(\mathrm{P}<0,05)$. EPR: erro-padrão residual.

O triticale apresenta componentes celulares como os PNAs, que dificultam a digestão dos elementos protéicos e energéticos (Hogberg e Lindberg, 2004). Isso diminui o valor energético do triticale ao compará-lo com o milho. O principal constituinte dos PNAs no triticale são as arabinoxilanas (50\%), que estão associadas às proteínas (Knudsen, 1997). Essa característica molecular dificulta a ação das enzimas endógenas na degradação dos componentes protéicos da dieta (Yin et al., 2000). A diminuição da proteína digestível aparente na dieta com $60 \%$ de triticale sem enzimas pode ser atribuída ao efeito negativo dos PNAs. Em dietas com arabinoxilanas, a secreção de $\mathrm{N}$ endógeno aumenta, elevando a excreção fecal de $\mathrm{N}$ (Yin et al., 2000). À medida que se substitui o milho por triticale, há redução linear dos coeficientes de digestibilidade da energia bruta (Furlan et al., 1999) e da matéria seca (Myer et al., 1989). Em dietas com $67 \%$ de triticale, no entanto, a energia digestível e a metabolizável não são alteradas (Brand et al., 1995). As respostas digestivas e metabólicas dos estudos com triticale são conflitantes. É possível que diferentes condições edafoclimáticas das regiões produtoras afetem as características químicas e físicas dos cereais de inverno (Cromwell et al., 2000).

As arabinoxilanas são hidrolisadas por enzimas exógenas específicas, como a xilanase e $\beta$ glucanase (Hogberg e Lindberg, 2004). A adição dessas enzimas nas dietas hidrolisa as paredes celulares dos PNAs, melhorando a digestibilidade dos componentes protéicos e energéticos. Neste experimento, as enzimas 
tiveram efeito sobre a proteína digestível nas dietas com $30 \%$ e $60 \%$ de triticale. A influência das enzimas na digestibilidade dos ingredientes, entretanto, depende da disponibilidade de substrato (Knudsen e Hansen, 1991). Isso pode explicar a ausência de efeito das enzimas na dieta-controle.

O balanço do $\mathrm{N}$ é apresentado na Tab. 4. Não houve interação triticale $\mathrm{x}$ enzimas, nem efeito de tratamentos e enzimas. Os resultados de $\mathrm{N}$ ingerido foram similares entre os tratamentos com diferentes níveis de triticale $(49,8 ; 51,2$ e $50,2 \mathrm{~g} / \mathrm{dia})$ e com ou sem enzimas $(50,5$ e 50,4 $\mathrm{g} /$ dia). Os resultados são semelhantes aos de outros estudos de digestão e metabolismo do N de suínos em crescimento (Otto et al., 2003; Fabian et al., 2004). Ingredientes fibrosos e com presença de PNAs estimulam a fermentação no intestino grosso, aumentando a população microbiana (Wenk, 2001). Isso aumenta a transferência de uréia plasmática para o intestino grosso, sendo convertida em amônia pelas bactérias ureáticas e utilizada para a síntese de proteína microbiana (Mamlof e Hakansson, 1984). Esse processo aumenta o $\mathrm{N}$ fecal e reduz o urinário (Galassi et al., 2004). Os baixos teores de fibra nas dietas experimentais $(<4,0 \%)$ podem ter sido insuficientes para desencadear este processo.

Tabela 4. Nitrogênio ingerido (Ni), excretado nas fezes (Nf) e na urina (Nu), absorvido (Na), retido (Nr) e retido em função do absorvido (Nr/a) de suínos alimentados com dietas contendo diferentes níveis de inclusão de triticale com ou sem adição de enzimas

\begin{tabular}{|c|c|c|c|c|c|c|}
\hline Dieta & $\mathrm{Ni}, \mathrm{g} / \mathrm{dia}$ & $\mathrm{Nf}, \mathrm{g} / \mathrm{dia}$ & $\mathrm{Nu}, \mathrm{g} / \mathrm{dia}$ & $\mathrm{Na}, \mathrm{g} / \mathrm{dia}$ & $\mathrm{Nr}, \mathrm{g} / \mathrm{dia}$ & $\mathrm{Nr} / \mathrm{a}, \%$ \\
\hline \multicolumn{7}{|l|}{ Nível de triticale } \\
\hline $0 \%$ & 49,80 & 6,16 & 10,12 & 43,66 & 33,55 & 76,88 \\
\hline $30 \%$ & 51,24 & 6,13 & 12,58 & 45,12 & 32,54 & 72,13 \\
\hline $60 \%$ & 50,19 & 5,59 & 10,55 & 44,60 & 34,04 & 76,43 \\
\hline \multicolumn{7}{|l|}{ Enzima } \\
\hline Sem enzima & 50,46 & 5,75 & 11,19 & 44,70 & 33,51 & 74,91 \\
\hline Com enzima & 50,40 & 6,18 & 11,03 & 44,22 & 33,20 & 75,25 \\
\hline EPR & 0,52 & 1,89 & 0,44 & 0,44 & 1,98 & 4,32 \\
\hline \multicolumn{7}{|l|}{$\mathrm{P}$} \\
\hline Triticale & 0,30 & 0,49 & 0,81 & 0,49 & 0,80 & 0,84 \\
\hline Enzimas & 0,86 & 0,28 & 0,91 & 0,29 & 0,88 & 0,94 \\
\hline Triticale $\mathrm{x}$ enzimas & 0,09 & 0,28 & 0,32 & 0,27 & 0,24 & 0,33 \\
\hline
\end{tabular}

EPR: erro-padrão residual; Ni utilizado como covariável.

A inclusão de até $67 \%$ de triticale nas dietas não altera o balanço do N (Brand et al., 1995), devido ao fato de os teores de aminoácidos serem semelhantes ou superiores aos do milho (Myer et al., 1996). A adição de enzimas não altera o balanço de $\mathrm{N}$ em dietas com uso de triticale (Bedford, 1995). O efeito das enzimas depende da presença de substrato, como os PNAs no triticale. A concentração desses componentes, contudo, pode variar de acordo com as características ambientais do lugar onde $\mathrm{o}$ triticale é cultivado (Anthony e Blakeney, 2005) e com o genótipo (Robert, 1985).

Os resultados da ingestão, excreção e absorção de P são apresentados na Tab. 5. Para a dinâmica do $P$, não houve diferenças nas variáveis estudadas para os diferentes níveis de triticale, nem para suas interações com enzimas. $\mathrm{Na}$ maioria dos cereais, $70 \%$ do $\mathrm{P}$ está sob a forma de fitato, que apresenta baixa digestibilidade, influenciando na absorção do $\mathrm{P}$ e da proteína (Mroz et al., 1994; Sands et al., 2001). A maioria das plantas apresenta atividade fitásica, mas o nível e a ação nos grãos variam entre os cereais (Barrier-Guillot et al., 1996). O triticale, por exemplo, apresenta alta atividade fitásica endógena, que pode aumentar a degradação do ácido fítico em $97 \%$ em relação às dietas à base de milho e farelo de soja para suínos (Kemme et al., 1998). Neste estudo, entretanto, não foi observado efeito do triticale sobre a digestão do fósforo. Isso pode ser explicado pela variação existente entre amostras do mesmo cereal em relação à presença de fitase (Maenz, 2001). 
Tabela 5. Fósforo ingerido (Pi), excretado nas fezes (Pf), absorvido (Pa), e absorvido em função do ingerido $(\mathrm{Pa} / \mathrm{i})$ de suínos alimentados com dietas contendo diferentes níveis de inclusão de triticale com ou sem adição de enzimas

\begin{tabular}{lcccc}
\multicolumn{1}{c}{ Dieta } & $\mathrm{Pi}, \mathrm{g} / \mathrm{dia}$ & $\mathrm{Pf}, \mathrm{g} / \mathrm{dia}$ & $\mathrm{Pa}, \mathrm{g} / \mathrm{dia}$ & $\mathrm{Pa} / \mathrm{i}, \%$ \\
\hline Nível de triticale & & & & \\
\hline $0 \%$ & 18,17 & 7,36 & 10,80 & 59,48 \\
$30 \%$ & 17,36 & 6,82 & 10,54 & 60,65 \\
$60 \%$ & 19,60 & 7,16 & 12,43 & 63,45 \\
Enzima & & & \\
Sem enzimas & 18,36 & 7,07 & 11,28 & 61,48 \\
Com enzimas & 18,28 & 7,15 & 11,13 & 60,74 \\
EPR & 1,02 & 0,31 & 0,31 & 1,68 \\
P & & & & 0,08 \\
Triticale & 0,09 & 0,08 & 0,08 & 0,38 \\
Enzimas & 0,51 & 0,48 & 0,45 & 0,09 \\
Triticale enzimas & 0,07 & 0,09 & 0,09 & \\
\hline
\end{tabular}

EPR: erro-padrão residual; Pi utilizado como covariável.

\section{CONCLUSÕES}

A inclusão de até $60 \%$ de triticale em dietas para suínos não afeta a digestibilidade dos nutrientes, a energia digestível e metabolizável e o balanço do N, mas reduz a proteína digestível aparente. A adição de enzimas melhora a digestibilidade da proteína em dietas com 30 e $60 \%$ de inclusão de triticale. Deste modo, sob o aspecto digestível, a inclusão de $60 \%$ de triticale com adição de enzimas aumenta a disponibilidade de proteína das dietas.

\section{AGRADECIMENTOS}

Os autores agradecem ao Conselho Nacional para o Desenvolvimento Científico e Tecnológico (CNPq) e à Comissão de Aperfeiçoamento de Pessoal de Ensino Superior (CAPES), pelas bolsas concedidas, e à Fundação de Amparo à Pesquisa do Estado do Rio Grande do Sul (FAPERGS), pelo apoio financeiro.

\section{REFERÊNCIAS BIBLIOGRÁFICAS}

ANTHONY, B; BLAKENEY, P.C.F. Determination of non-starch polysaccharides in cereal grains with near-infared reflectance spectroscopy. Mol. Nut. Food Res., v.49, p.546-550, 2005.

BARRIER-GUILLOT, B.; CASADO, P.; MAUPETITE, P. et al. Wheat Phosphorus availability. 2. In vivo study in broilers in pigs, relathionship with endogenous phytasic activity and phytic phosphorus content in wheat. J. Sci. Food Agr., v.70, p.69-74, 1996.
BEDFORD, M.R. Mechanism of action and potential environmental benefits from the use of feed enzymes. Anim. Feed Sci. Technol., v.53, p.145-155, 1995.

BRAND, T.S.; OLCKERS, R.C.; VAN DER MERWE, J. P. Triticale (Tritico secale) as substitute for maize in pig diets. Anim. Feed Sci. Technol., v.53, p.345-352, 1995.

CROMWELL, G.L.; CLINE, T.R.; CRENSHAW, J.D. et al. Variability among sources and laboratories in analyses of wheat middlings. NCR-42 Committee on Swine Nutrition. J. Anim. Sci., v.78, p.2652-2658, 2000.

FABIAN, J.; CHIBA, L.I.; FROBISH, L.T. et al. Compensatory growth and nitrogen balance in growerfinisher pigs. J. Anim. Sci., v.82, p.2579-2587, 2004.

FEDALTO, L. M.; TULESKI, G.L.R.; WARPECHOSKI, M.B. et al. Ração de farelo de soja e de soja integral extrusada e diferentes níveis de substituição do milho por titricale na alimentação animal. 1. Desempenho no crescimento de suínos. Arch. Vet. Sci., v.4, p.65-67, 1999.

FIREMAN, F.A.T.; FIREMAN, A.K.B.A.T. Enzimas na alimentação de suínos. Cienc. Rural, v.28, p.173178, 1998.

FURLAN, A.C.; MIKAMI, F.; MOREIRA, I. et al. Uso do triticale (Triticum turgidosecale) na alimentação de suínos em crescimento $(25-60 \mathrm{~kg})$. Rev. Bras. Zootec., v.28, p.1042-1049, 1999.

GALASSI, G.; CROVETTO, G.M.; RAPETTI, L. et al. Energy and nitrogen balance in heavy pigs fed different fibre sources. Livest. Prod. Sci., v.85, p.253262, 2004.

HOGBERG, A.; LINDBERG, J.E. Influence of cereal non-starch polysaccharides and enzyme supplementation on digestion site and gut environment 


\section{Hauschild et al.}

in weaned piglets. Anim. Feed Sci. Technol., v.116, p.113-128, 2004.

JORGENSEN, H.; ZHAO, X.; EGGUM, B. The influence of dietary fibre and environmental temperature on the development of the gastrointestinal tract, digestibility, degree of fermentation in the hindgut and energy metabolism in pigs. Br. J. Nutr., v.75, p.365-378, 1996.

KEMME, P.A.; JONGBLOED, A.W.; MROZ, Z. et al. Diurnal variation in degradation of phytic acid by plant phytase in the pig stomach. Livest. Prod. Sci., v.54, p.33-44, 1998.

KNUDSEN, K. E. B. Carbohydrate and lignin contents of plant materials used in animal feeding. Anim. Feed Sci. Technol., v.67, p.319-338, 1997.

KNUDSEN, K.E.B.; HANSEN, I. Gastrointestinal implications in pigs of wheat and oat fractions. Brit. J. Nut., v. 65, p.217-232, 1991.

MAENZ, D.D. Enzymatic characteristics of phytases as they relate to their use in animal feeds. In : BEDFORD, M.R.; PARTRIDGE, G.G. (Eds.). Enzymes in farm animal nutrition. New York: CABI Publishing, 2001. p. 61-84.

MAMLOF, K.; HAKANSSON, J. The effect of dietary fibre level on the diurnal pattern of urinary nitrogen excretion in swine. Swed. J. Agr. Res., v.14, p.53-57, 1984.

MATTERSON, L.D.; POTTER, L.M.; STUTZ, M.W. et al. The metabolizable energy of feed ingredients for chickens. Res. Rep., v.7, p.3-11, 1965.

MROZ, Z.; JONGBLOED, A.W.; KEMME, P.A. Apparent digestibility and retention of nutrients bound to phytate complexes as influenced by microbial phytase and feeding regimen in pigs. J. Anim. Sci., v.72, p.126-132, 1994.

MYER, R.O.; BARNETT, R.D.; CORNELL, J.A. et al. Nutritive value of diets containing triticale and varying mixtures of triticale and maize for growingfinishing swine. Anim. Feed Sci. Technol., v.22, p.217225, 1989.

MYER, R.O.; BRENDEMUHL, J.H.; BARNETT, R.D. Crystalline lysine and threonine supplementation of soft red winter wheat or triticale, low-protein diets for growing-finishing swine. J. Anim. Sci., v.74, p.577-583, 1996.

NOBLET, J.; SHI, X.S.; DUBOIS, S. Metabolic utilization of dietary energy and nutrients for maintenance energy requirements in sows: basis for a net energy system. Br. J. Nutr., v.70, p.407-419, 1993.
NUTRIENT requirements of swine. 10 ed. Washington: National Academy of Science, 1998. $189 \mathrm{p}$.

OFFICIAL methods of analysis. 15 ed. Washington: AOAC, 1990. 1117p.

OTTO, E.R.; YOKOYAMA, M.; KU, P.K. et al. Nitrogen balance and ileal amino acid digestibility in growing pigs fed diets reduced in protein concentration. J. Anim. Sci., v.81, p.1743-1753, 2003.

OWSLEY, W.F.; HAYDON, K.D.; LEE, R.D. Effect of variety and planting location on the value of triticale for swine. J. Anim. Sci., v.65, suppl.1, p.34, 1987. (Abstr.).

POINTILLART, A. Importance of phytates and cereal phytases in the feeding of pigs. In: WENK, C.; BOESSINGER, M. (Eds). Enzymes in animal nutrition. Switzerland: Kartause Ittingen, 1993. p.192199.

ROBERT, J.H.A comparison of the non-starch carbohydrates in cereal grains. J. Sci. Food. Agric., v.36, p.1243-1253, 1985.

ROSTAGNO, H.S.; ALBINO, L.F.T.; DONZELE, J.L. et al. Tabelas brasileiras para aves e suínos. Composição de alimentos e exigências nutricionais. Viçosa: UFV, 2000. 141p.

ROSTAGNO, H.S.; ALBINO, L.F.T.; DONZELE, J.L. et al. Tabelas brasileiras para aves e suinos. Composição de alimentos e exigências nutricionais. Viçosa: UFV, 2005. 186p.

SANDS, J.S.; RAGLAND, D.; JOERN, B.C. et al. Phosphorus bioavailability, growth performance, and nutrient balance, in pigs fed high available phosphorus corn and phytase. J. Anim. Sci., v.79, p.2134-2142, 2001.

USER'S guide: statistical analysis system. Release 8.0. Cary, NC: SAS Institute, 2000. (01 CD-ROM).

SHIMADA, A.; CLINE, T.R.; ROGLOR, J.C. Nutritive value of triticale the nonruminante. J. Anim. Sci., v.38, p.935-940, 1974.

WENK, C. The role of dietary fibre in the digestive physiology of the pig. Anim. Feed Sci. Technol., v.90, p.21-33, 2001.

YIN, Y.-L.; MCEVOY, J.D.G.; SCHULZE, H. et al. Apparent digestibility (ileal and overall) of nutrients and endogenous nitrogen losses in growing pigs fed wheat (var. Soissons) or its by-products without or with xylanase supplementation. Livest. Prod. Sci., v.62, p.119-132, 2000. 